\title{
Characterization of phenotypic variants of Clavibacter michiganensis subsp. michiganensis isolated from Capsicum annuum
}

\author{
Kyu-Ock Yim • Hyok-In Lee • Jung-Hee Kim • \\ Seung-Don Lee $\cdot$ Jung-Hee Cho $\cdot$ Jae-Soon Cha
}

Accepted: 12 December 2011 /Published online: 24 December 2011

(C) The Author(s) 2011. This article is published with open access at Springerlink.com

\begin{abstract}
Phenotypic variants of Clavibacter michiganensis subsp. michiganensis $(\mathrm{Cmm})$ were isolated from pepper fields and from pepper seeds during quarantine inspections. All strains isolated from pepper (pepper isolates) produced orange-coloured colonies with lower mucoidy than typical $\mathrm{Cmm}$ strains isolated from tomato (tomato isolates). However, the results of ELISA, fatty acid analysis, 16S rDNA sequencing, and PCR analysis showed that all pepper isolates were similar enough to be identified as $\mathrm{Cmm}$. In addition to phenotypic variations, the pepper isolates showed different pathogenic and genetic characteristics from tomato isolates from the USA, Europe, or other countries. They could be clearly distinguished in terms of pathogenicity, as they showed increased pathogenicity to pepper but reduced pathogenicity to tomato. Tomato isolates caused strong wilting and canker in
\end{abstract}

Kyu-Ock Yim and Hyok-In Lee contributed equally to the work

K.-O. Yim $(\bowtie) \cdot$ H.-I. Lee $\cdot$ J.-H. Kim

National Plant Quarantine Service,

175 Anyangro,

Anyang, Kyoungki-do 430-016, Korea

e-mail: koyim@korea.kr

S.-D. Lee

Rural Development Administration,

150 Suinro,

Suwon, Kyoungki 441-707, Korea

J.-H. Cho • J.-S. Cha

Department of Plant Medicine,

Chungbuk National University,

52 Naesudongro,

Cheongju, Chungbuk 361-763, Korea tomato, but caused only canker and no wilting in pepper and bell pepper. However, pepper isolates caused no wilting, even in tomato, and only caused canker in the three host plants. In addition, compared to tomato isolates, pepper isolates showed increased colonization efficiency and caused a greater reduction in shoot dry weight in pepper. Pepper and tomato isolates could be separated into two groups according to host origin on the basis of $16 \mathrm{~S}$ rDNA and ITS sequence analysis. They also showed different repPCR genomic fingerprints. All pepper isolates showed higher cellulase activity than tomato isolates on M9CMC plates. However, two plasmid-borne virulence genes of $\mathrm{Cmm}$, pat-1, and celA, were not detected in any pepper isolates by PCR. Furthermore, PCR for pathogenicity-related genes located on a pathogenicity island (PAI) revealed that all tomato isolates were positive for these genes, whereas the pepper isolates did not show any PCR products for the $c h p C$, chp $\mathrm{G}, p p a \mathrm{~A}$, or tom $\mathrm{A}$ genes. Therefore, we suggest that the pepper isolates may represent a separate $\mathrm{Cmm}$ population that has evolved within the limits of this host.

Keywords Bacterial canker. Clavibacter michiganensis subsp. michiganensis · Pepper isolate

\section{Introduction}

Bacterial canker of tomato (Solanum lycopersicon), caused by the gram-positive bacterium Clavibacter 
michiganensis subsp. michiganensis (Smith) Davis et al. $(\mathrm{Cmm})$, is an important and widespread disease causing major economic losses in commercial tomato production (Gartemann et al. 2003; Gleason et al. 1993). In many countries, Cmm is regulated by quarantine procedures to minimize the introduction of the pathogen through commercial seeds, which are considered the most important source of inoculum; however, the pathogen has still been reported in most tomato-growing countries (Gartemann et al. 2003). In order to isolate $\mathrm{Cmm}$ from seeds and plants, various semi-selective media have been developed and improved (Gleason et al. 1993). In addition to traditional microbiological tests, various techniques, such as ELISA, fatty acid analysis, rDNA sequence analysis, PCR, and DNA fingerprinting, have been used for identification of Cmm (Gleason et al. 1993).

The Clavibacter michiganensis $(\mathrm{Cm})$ species is divided into five subspecies on the basis of host specificity and biochemical and genetic characteristics: Cm. subsp. sepedonicus (Cms), Cm. subsp. michiganensis (Cmm), Cm. subsp. insidiosus (Cmi), Cm. subsp. tesselarius (Cmt), and $\mathrm{Cm}$. subsp. nebraskensis (Cmn) (Gartemann et al. 2003). Although tomato is the primary host of $\mathrm{Cmm}$, several other plants belonging to the family Solanaceae-pepper (Capsicum annuum), bell pepper (Capsicum sativum), and eggplant (Solanum melongena) - have been found to be naturally infected with $\mathrm{Cmm}$ in the field. However, these infections are unusual and are described in brief reports in many cases (Burokiene et al. 2005; Latin et al. 1995; Lewis-Ivey and Miller 2000).

$\mathrm{Cmm}$ spreads throughout the plant via the xylem vessels and induces systemic symptoms, including wilting, stem canker, vascular discolouration, and plant death (Gartemann et al. 2003; Gleason et al. 1993). Cmm titers in tomato may reach $10^{9}$ bacteria per $g$ plant tissue (Meletzus et al. 1993). The development of wilting symptoms in tomato is induced by the celA and pat-1 genes, which are located on the pCM1 and pCM2 plasmids of $\mathrm{Cmm}$ strain NCPPB382 (Gartemann et al. 2003, 2008; Meletzus et al. 1993). In addition, a large $(\sim 129 \mathrm{~kb})$ pathogenicity island (PAI) with low $\mathrm{G}+\mathrm{C}$ content was discovered in the chromosome of Cmm NCPPB382 (Gartemann et al. 2008). Numerous genes in the PAI might be involved in $\mathrm{Cmm}$-tomato interactions such as the colonization of the tomato plant, hypersensitive reactions, and suppression of host defence reactions (Burger et al. 2005; Gartemann et al. 2008; Stork et al. 2008).

Various atypical strains of $\mathrm{Cmm}$ with phenotypic and genotypic variations have been reported in previous studies. Strains that show variant colony morphology on nutrient-rich medium have been reported, which occasionally include dry, sticky, less mucoid, pink, red, orange, white, or colourless strains (Davis and Vidaver 2001; Hayward and Waterston 1964; Kaneshiro et al. 2006). Cmm strains with variations in virulence have also been isolated from seeds and plants (Kaneshiro et al. 2006; Kaneshiro and Alvarez 2001; Louws et al. 1998). Despite the presence of these variations in $\mathrm{Cmm}$ strains, their characteristics and the relationships of these to their host preferences have never been studied in detail.

$\mathrm{Cmm}$ isolates collected from the USA or Europe show generally conserved sequences in the internal transcribed spacer region (ITS region) and 16S rDNA gene (Lee et al. 1997b; Pastrik and Rainey 1999). It was also reported that $\mathrm{Cmm}$ can be subdivided into four or six distinct groups on basis of the diversity in repetitive sequence-based PCR (rep-PCR) fingerprint patterns (Louws et al. 1998; Nazari et al. 2007; Kleitman et al. 2008). More recently, genetic diversity related to geographical area was observed within the $\mathrm{Cmm}$ population (De Leon et al. 2009; Ignatov et al. 2004; Kaneshiro et al. 2006; Nazari et al. 2007). Among the five $\mathrm{Cm}$ subspecies, the relatively high genetic diversity of $\mathrm{Cmm}$ strains was confirmed by PCR-RFLP and PFGE analysis (Kleitman et al. 2008; Waleron et al. 2011).

The $\mathrm{Cmm}$ pathogen was first isolated from peppers in 1997-1998, during a disease outbreak in pepper fields in Korea, and most isolates showed different phenotypes from the typical description of the Cmm strains that had been isolated from tomato (Lee et al. 1999). In Korea, most commercial tomato and pepper seeds are imported from Asian countries, and the detection rate of $\mathrm{Cmm}$ in imported seeds during quarantine inspections has increased. In quarantine laboratory tests, Cmm isolates from imported pepper seeds have consistently exhibited similar morphological characteristics that are different from those of tomato isolates. This study aimed to determine the variations in morphological, molecular, and pathogenic properties of $\mathrm{Cmm}$ isolates from pepper. 


\section{Materials and methods}

Bacterial strains and culture conditions

$\mathrm{Cmm}$ strains were obtained from the BCCM/LMG Bacteria Collection (Gent, Belgium) and Korean Agricultural Culture Collection (Suwon, Korea) (Table 1). The Cmm pepper isolates used in this study were isolated from imported pepper seeds during quarantine inspections and from pepper fields in Korea. A KBST semi-selective medium (Gleason et al. 1993) was used to isolate $\mathrm{Cmm}$. After incubation at $27^{\circ} \mathrm{C}$ for 7 days, the colonies exhibiting $\mathrm{Cmm}$-like morphology were selected for growth in pure culture by streaking onto plates of NBY agar medium. All the isolates were incubated on NBY or YDC medium at $27^{\circ} \mathrm{C}$ for 48-72 $\mathrm{h}$ prior to further analysis.

\section{Identification of $\mathrm{Cmm}$}

All strains were initially identified using ELISA according to the protocol provided by the manufacturer (Agdia, Inc., Elkhart, IN, USA). PCR analysis for identification was performed using three $\mathrm{Cmm}$ primer pairs: CMR16F1/16R1, ClaF1/ClaR2, and $\mathrm{Cm} 3 / \mathrm{Cm} 4$ (Table 2). Positive strains were identified and characterized using the Sherlock Microbial Identification System (MIDI Inc., Newark, DE, USA).

Pathogenicity and colonization tests

Ten representative $\mathrm{Cmm}$ strains were selected for further pathogenicity tests on three host plants. Tomato (var. Moneymaker), pepper (var. Manitta), and bell pepper (var. Spirit) seeds were planted in $8 \times 8 \mathrm{~cm}$ trays and grown in a greenhouse at $25-30^{\circ} \mathrm{C}$ and $80 \%$ relative humidity. Each plant was inoculated between the 3- and 4-leaf stage of growth by cutting off the top of the youngest leaf with scissors that had been dipped into a bacterial suspension $\left(10^{8} \mathrm{CFU} / \mathrm{ml}\right)$ (Poysa 1993). The monitoring of symptom development was started after 10 days of inoculation, at which time unilateral wilting of the leaves was first observed in tomato seedlings. All plants were examined daily over a period of 25 days for the development of wilting and canker symptoms.

In order to measure the reduction in shoot dry weight of inoculated plants, the shoots of seedlings were harvested 25 days after inoculation. The harvested samples were dried at $80^{\circ} \mathrm{C}$ for 3 days, and their weight was measured. Six plants of each strain were inoculated, and all tests were conducted three times.

At 25 days after inoculation, the shoot of each plant was harvested, frozen separately in liquid nitrogen, and then ground to powder with a sterile pestle and mortar. The powder was suspended in PBST buffer (1 ml buffer/g fresh weight), and $100-\mu l$ aliquots of progressive tenfold serial dilutions $\left(1-10^{-4}\right)$ were plated on KBST. Plates were incubated at $27^{\circ} \mathrm{C}$ for 7 days to determine the number of colony-forming units (CFU). For each strain, three plants were inoculated and the same tests were repeated three times.

\section{DNA extraction and PCR}

The primers used in this study are listed in Table 2. Total DNA of $\mathrm{Cmm}$ strains was extracted using the DNeasy Mini Kit (Qiagen Inc., Valencia, CA, USA) according to the manufacturer's protocol for grampositive bacteria. General PCR for identification was performed using HotStart PCR PreMix (Bioneer, Daejeon, Korea). Takara Ex Taq PCR Kit (Takara, Kyoto, Japan) was used for genomic fingerprinting and sequence analysis. Rep-PCR was performed according to the method described in Louws et al. (1998), with ERIC-1R, ERIC-2, and BOX A1R primers (Table 2). PCR was performed on Gene Amp PCR System 2400 (Perkin-Elmer, Foster City, CA, USA). The amplified products were subjected to electrophoresis on a $1.2 \%$ agarose gel and then stained with ethidium bromide. The analysis of rep-PCR products was performed with a LabChip GX-DNA analysis system (Caliper Life Sciences Inc., MA, USA). Results of rep-PCR were recorded as presence (1) or absence (0) of product, and agglomerative hierarchical cluster (AHC) analysis was applied using the unweighted pair-group average method (UPGMA) with Dice dissimilarity matrix on Microsoft Excel software with the XLSTAT (T. Fahmy, Paris, France) add-in.

Sequence analysis

PCR for sequence analysis of the $16 \mathrm{~S}$ rDNA gene and ITS region was performed on selected $\mathrm{Cmm}$ subsets from tomato and pepper isolates using the universal primer pair FGPS-6/FGPL-132 (Table 2). Each PCR product was cloned with the pGEM-T-Easy vector 


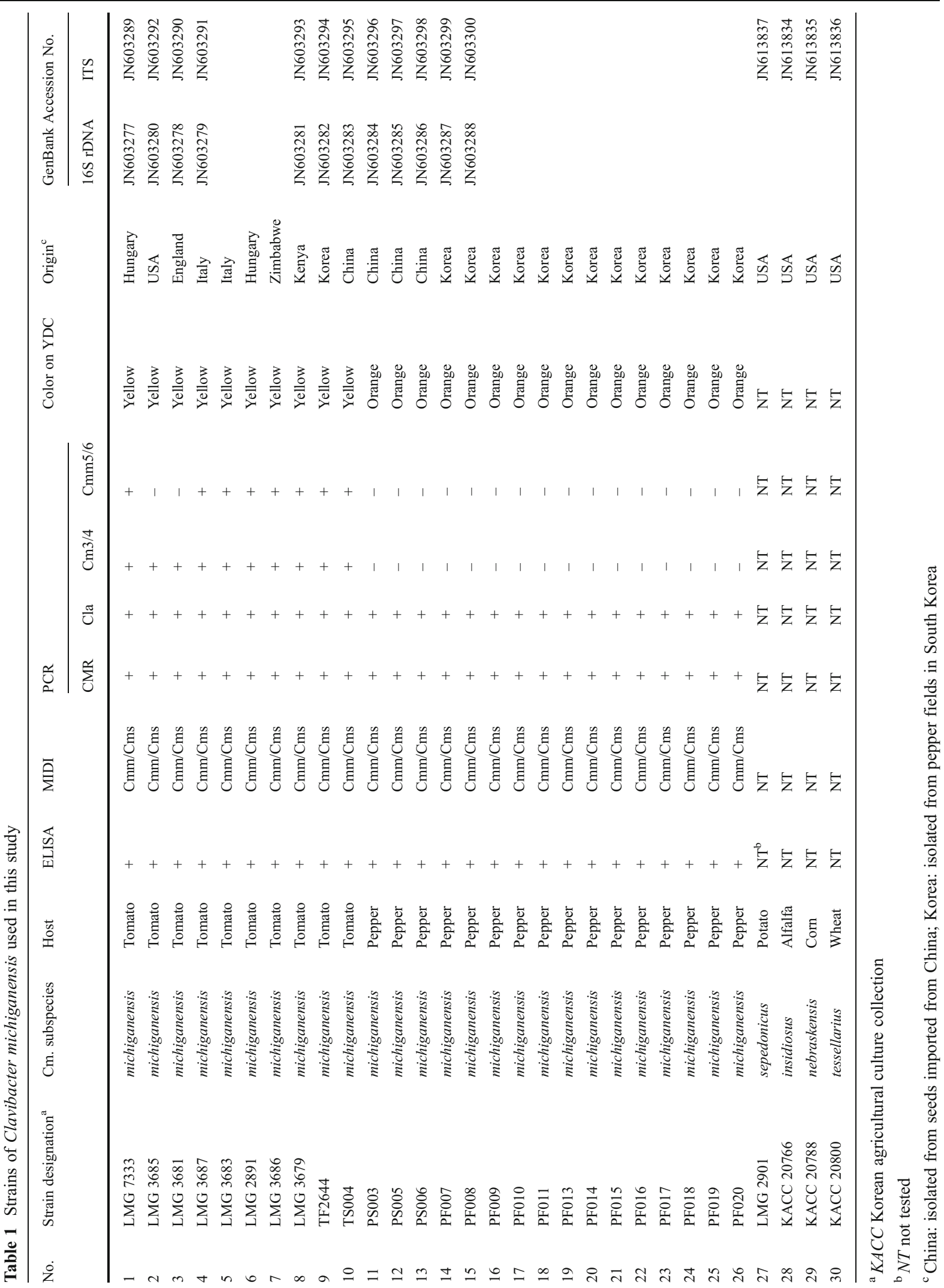


Table 2 Sequences of primers used in this study

\begin{tabular}{|c|c|c|c|}
\hline Primer & Sequence $\left(5^{\prime}-3^{\prime}\right)$ & Target $^{\mathrm{a}}$ & Reference \\
\hline $\begin{array}{l}\text { CMR16F1 } \\
\text { CMR16R1 }\end{array}$ & $\begin{array}{l}\text { GTGATGTCAGAGCTTCCTCTGGCGGAT } \\
\text { GTACGGCTACCTTGTTACGACTTAGT }\end{array}$ & 16S-rRNA & Lee et al. (1997a) \\
\hline $\begin{array}{l}\text { ClaF1 } \\
\text { ClaR2 }\end{array}$ & $\begin{array}{l}\text { TCATTGGTCAATTCTGTCTCCC } \\
\text { TACTGAGATGTTTCACTTCCCC }\end{array}$ & ITS region & Peng et al. (2005) \\
\hline $\begin{array}{l}\mathrm{Cm} 3 \\
\mathrm{Cm} 4\end{array}$ & $\begin{array}{l}\text { CCTCGTGAGTGCCGGGAACGTATCC } \\
\text { CCACGGTGGTTGATGCTCGCGAGAT }\end{array}$ & pCM1 & Santos et al. (1997) \\
\hline $\begin{array}{l}\text { FGPS-6 } \\
\text { FGPL-132 }\end{array}$ & $\begin{array}{l}\text { GGAGAGTTAGATCTTGGCTCAG } \\
\text { CCGGGTTTCCCCATTCGG }\end{array}$ & 16S-ITS-23S & Normand et al. (1992) \\
\hline $\begin{array}{l}16 \mathrm{~S} \\
23 \mathrm{~S}\end{array}$ & $\begin{array}{l}\text { TTGTACACACCGCCCGTCA } \\
\text { GGTACCTTAGATGTTTCAGTTC }\end{array}$ & ITS region & Kostman et al. (1992) \\
\hline BOX A1R & CTACGGCAAGGCGACGCTGACG & rep-PCR & Louws et al. (1998) \\
\hline $\begin{array}{l}\text { ERIC-1R } \\
\text { ERIC-2 }\end{array}$ & $\begin{array}{l}\text { ATGTAAGCTCCTGGGGATTCAC } \\
\text { AAGTAAGTGACTGGGGTGAGCG }\end{array}$ & rep-PCR & Louws et al. (1998) \\
\hline $\begin{array}{l}\mathrm{Cmm}-5 \\
\mathrm{Cmm}-6\end{array}$ & $\begin{array}{l}\text { GCGAATAAGCCCATATCAA } \\
\text { CGTCAGGAGGTCGCTAATA }\end{array}$ & pat-1 & Dreier et al. (1995) \\
\hline $\begin{array}{l}\text { P1rep } \\
\text { P3rep }\end{array}$ & $\begin{array}{l}\text { CGTACCCCGAGAACCGGGG } \\
\text { GCGCCCGTGTCGAACATT }\end{array}$ & pat-1rep & Dreier et al. (1997) \\
\hline $\begin{array}{l}\text { cel-578up } \\
\text { cel-2752low }\end{array}$ & $\begin{array}{l}\text { ATGGCTTCCCTACGATCC } \\
\text { ACAGGGTAGAAGCGGGAGG }\end{array}$ & celA & Jahr et al. (2000) \\
\hline $\begin{array}{l}\text { pCRcel-593 } \\
\text { pCRcel-1860 }\end{array}$ & $\begin{array}{l}\text { TCCTTATATGACATTTCGCC } \\
\text { GCCACTTCGCTGATACAG }\end{array}$ & $\mathrm{CD}$ of celA & Jahr et al. (2000) \\
\hline $\begin{array}{l}\text { PFC3 } \\
\text { PFC5 }\end{array}$ & $\begin{array}{l}\text { GGTACGAAGTTCGAGACGAC } \\
\text { TGTAGCGGTGAGTCGTGGTGA }\end{array}$ & CBD of celA & Kleitman et al. (2008) \\
\hline $\begin{array}{l}\text { tomA-F } \\
\text { tomA-R }\end{array}$ & $\begin{array}{l}\text { CGAACTCGACCAGGTTCTCG } \\
\text { GGTCTCACGATCGGATCC }\end{array}$ & tomA & Kleitman et al. (2008) \\
\hline $\begin{array}{l}\text { ppaA-F } \\
\text { ppaA-R }\end{array}$ & $\begin{array}{l}\text { CATGATATTGGTGGGGAAAG } \\
\text { CCCCGTCTTTGCAAGACC }\end{array}$ & ppaA & Kleitman et al. (2008) \\
\hline $\begin{array}{l}\text { chpC-F } \\
\text { chpC-R }\end{array}$ & $\begin{array}{l}\text { GCTCTTGGGCTAATGGCCG } \\
\text { GTCAGTTGTGGAAGATGCTG }\end{array}$ & $\operatorname{chpC}$ & Kleitman et al. (2008) \\
\hline $\begin{array}{l}\text { chpG-F } \\
\text { chpG-R }\end{array}$ & $\begin{array}{l}\text { GACAACATGACCCTGCACTG } \\
\text { TCGGGGTGTAGACAAGGAAG }\end{array}$ & $\operatorname{chp} \mathrm{G}$ & Kleitman et al. (2008) \\
\hline
\end{tabular}

${ }^{\text {a }} C D$ catalytic domain; $C B D$ cellulose binding domain

system (Promega, Wisconsin, USA). The true clones were selected by M13 PCR amplification, and the PCR products were used as templates for sequencing. Sequencing was performed on an ABI 3730xl DNA sequencer (Applied Biosystems, CA, USA). Acquired sequences were compared with reference sequences using BLAST (http://blast.ncbi.nlm.nih.gov) and aligned using ClustalW software (Thompson et al. 1994). In addition, ITS region of four $\mathrm{Cm}$ subspecies were sequenced using the primer pair $16 \mathrm{~S} / 23 \mathrm{~S}$ by the same method because there is not enough ITS sequence data in GenBank (Table 2). Prior to construction of phylogenetic trees, the sequences of the $16 \mathrm{~S}$ rDNA gene and ITS region were separated from full alignments and adjusted to equal lengths. Phylogenetic analysis was performed using the MEGA 4.0 program (Kumar et al. 2004), and the phylogenetic tree was constructed using the neighbour-joining method (Saitou and Nei 1987).

Assay for cellulase activity

Cellulase activity of $\mathrm{Cmm}$ isolates was detected on M9CMC agar plates (Meletzus et al. 1993). A single colony grown on NBY was inoculated onto an M9CMC plate using a sterilized tip and incubated for 4 days at $26^{\circ} \mathrm{C}$. Plates were stained with $0.1 \%$ (wt/vol) Congo red for $10 \mathrm{~min}$ and then bleached three times with $1 \mathrm{M} \mathrm{NaCl}$. Cellulase activity was detected 
by clear zone formation. The same tests were repeated three times.

\section{Results}

Identification and characterization of $\mathrm{Cmm}$ strains

All $\mathrm{Cmm}$ strains isolated from tomato showed typical colony morphology (convex, mucoid, and pale yellow to yellow) on NBY and YDC media. In contrast, all strains isolated from pepper produced orangecoloured, less mucoid colonies (Fig. 1). Nevertheless, both tomato and pepper isolates gave positive results in commercial ELISA for detection of $\mathrm{Cmm}$ (Table 1). In fatty acid analysis using the MIDI system, all ELISA-positive strains showed high similarity with the $\mathrm{Cmm} / \mathrm{Cms}$ group (Table 1 ). The fatty acid composition of strains in the two groups of isolates were very similar to each other, although there are slight differences in levels of anteiso-heptadecanoic acid (a17:0) and palmitic acid (16:0), which were higher in pepper isolates (data not shown).

PCR was carried out with three primer pairs for identification of $\mathrm{Cmm}$, and the PCR patterns of the two groups were compared. All tested strains showed positive PCR results with the CMR16F1/CMR16R1 primer pair, which was designed from the 16S rDNA region for detection of $\mathrm{Cm}$ at the species level (Fig. 2-a and Table 1). With a $\mathrm{Cmm}$-specific primer pair, $\mathrm{ClaF} 1 / \mathrm{ClaR} 2$, derived from the ITS region, all collected strains were identified as $\mathrm{Cmm}$ by amplification of PCR products of the expected sizes. All tomato isolates gave strong bands of products with the ClaF1/ClaR2 primer pair, whereas only faint bands were observed with the pepper isolates (Fig. 2-b and Table 1). However, two of the 10 tomato isolates did

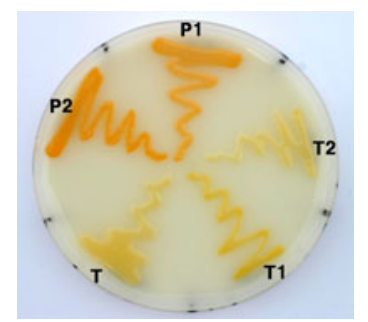

Fig. 1 Phenotypes of Clavibacter michiganensis subsp. michiganensis strains on YDC agar. T: LMG7333; T1: LMG3681; T2: LMG3685; P1: PF008; P2: PF007 not react with $\mathrm{Cmm} 5 / \mathrm{Cmm} 6$, which is also known to be a $\mathrm{Cmm}$-specific primer pair (Table 1). In addition, none of the pepper isolates gave a PCR product with the $\mathrm{Cm} 3 / \mathrm{Cm} 4$ primer pair, derived from the $\mathrm{pCM} 1$ plasmid, while all tomato isolates produced strong product bands with the same primer (Fig. 2-c and Table 1).

Pathogenicity and colonization in the 3 different hosts

The tomato and pepper isolates varied in pathogenicity and colonization efficiency in tomato, pepper, and bell pepper plants. All tested tomato isolates appeared to be very highly pathogenic to tomato seedlings. After 25 days of inoculation, all infected tomato seedlings showed strong wilting and canker symptoms, and over $80 \%$ of them were dead (Fig. 3; Table 3). In addition, the shoot dry weight of infected tomato plants was significantly reduced by $56 \%$ with the LMG7333 strain. However, in pepper plants, the tomato isolates caused minimal stem canker and leaf blight without wilting (Fig. 3; Table 3), and reduced the shoot dry weight by only $13 \%$ after 25 days (Table 4 ).

When pepper isolates were inoculated on tomato seedlings, wilting symptoms did not appear, although slight stem canker was observed in $50 \%$ of tomatoes, and leaf blight was seen on only $30 \%$ of seedlings. Shoot dry weight was reduced by approximately $15 \%$. When pepper seedlings were inoculated with pepper isolates, most of the seedlings showed stem and leaf blight, and the shoot dry weight was reduced by approximately $30 \%$ (Fig. 3; Table 4). In summary, we found that in comparison with tomato isolates, the pepper isolates showed reduced pathogenicity on tomato and increased pathogenicity on pepper.

When inoculated on bell pepper seedlings, the tomato and pepper isolates caused similar symptoms (Table 3) and a similar reduction in shoot dry weight (Table 4). These differences in symptoms were also observed in other commercial varieties of tomato, pepper, and bell pepper (data not shown).

The population sizes of tomato and pepper isolates in different hosts were compared in order to identify differences in colonization efficiency. In tomato, the tomato isolates were detected at levels over $10^{8} \mathrm{CFU} / \mathrm{g}$ after 25 days of inoculation, whereas pepper isolates showed population sizes under $10^{6} \mathrm{CFU} / \mathrm{g}$. In contrast, the population size in pepper reached approximately $10^{6} \mathrm{CFU} / \mathrm{g}$ for tomato strains and over $10^{8} \mathrm{CFU} / \mathrm{g}$ for 


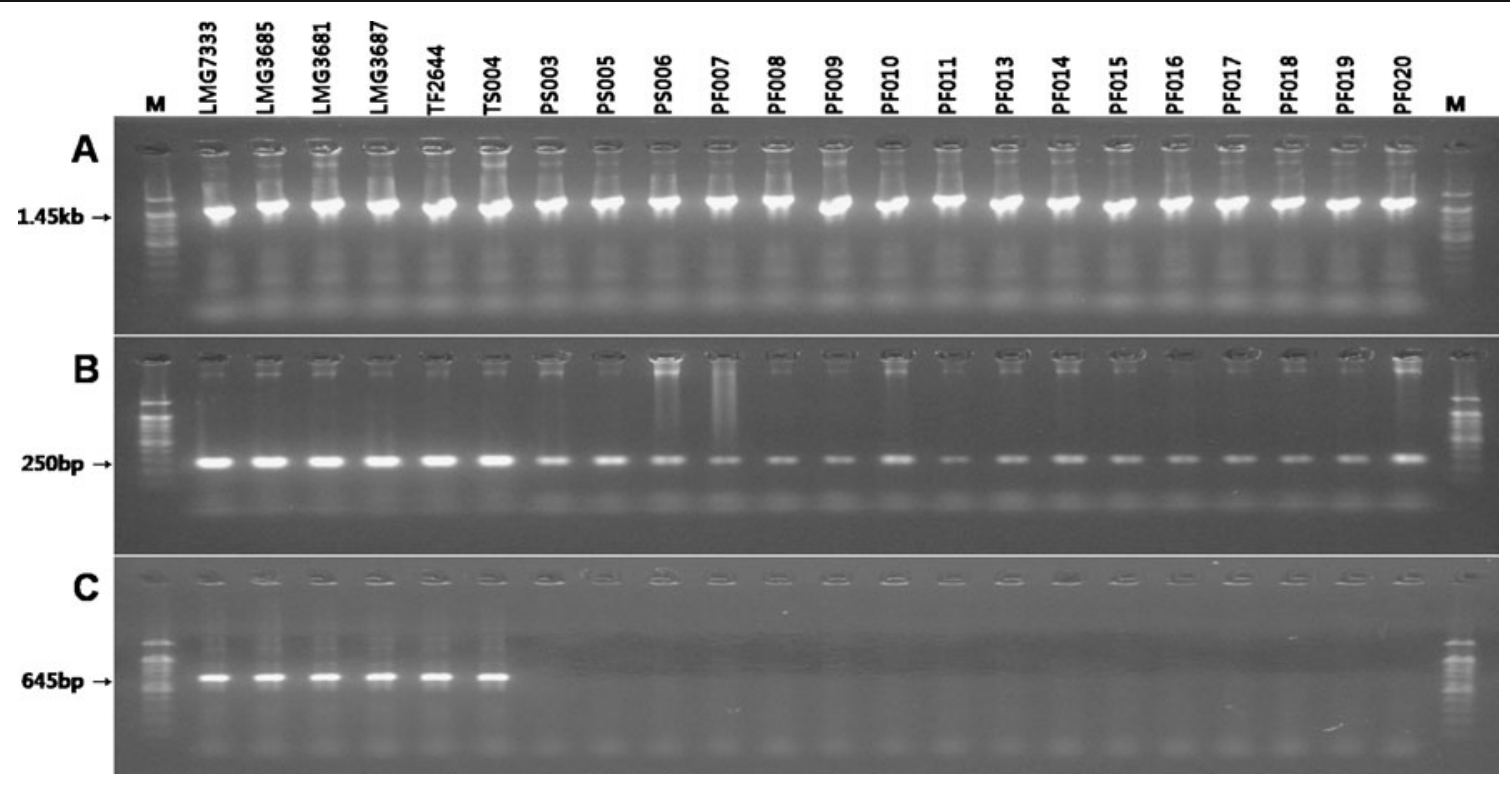

Fig. 2 PCR assay for detection Clavibacter michiganensis subsp. michiganensis using specific primers. a CMR16F1/CMR16R1; b ClaF1/ClaR2; c Cm3/Cm4; M: molecular marker

pepper strains. The $2 \mathrm{Cmm}$ groups showed a similar population size in bell pepper (Table 4). These results showed that pepper isolates have higher colonization efficiency in pepper plants, whereas that of tomato isolates was higher in tomatoes.

Genomic fingerprints of the $2 \mathrm{Cmm}$ groups

Genomic fingerprinting analysis using BOX and ERIC primers showed that $\mathrm{Cmm}$ isolates could be separated into two groups according to the host origin. The distinct differences between the two $\mathrm{Cmm}$ groups were easily observed from the overall patterns observed in BOX PCR. The polymorphisms of BOX PCR bands in the region around 1,500 bp to 2,000 bp allowed differentiation between the two $\mathrm{Cmm}$ groups. In addition, all pepper isolates showed common bands in the $800 \mathrm{bp}$ and $900 \mathrm{bp}$ regions (Fig. 4-a). ERIC PCR fingerprinting showed more polymorphic bands for each $\mathrm{Cmm}$ strain. However, tomato and pepper isolates could still be distinguished on the basis of the ERIC PCR banding patterns in the region around $500 \mathrm{bp}$ to $700 \mathrm{bp}$ (Fig. 4-b). A visual inspection of the dendrogram obtained using the UPGMA method shows that $\mathrm{Cmm}$ isolates are clustered in two groups (Fig. 5). This high dissimilarity in fingerprint patterns suggested that there is significant genetic diversity between the two $\mathrm{Cmm}$ groups.
Comparison of the 16S rDNA gene and ITS sequences

Approximately 2.1-kb DNA sequences encompassing the 16S rDNA gene, ITS region, and partial 23S rDNA gene were obtained from the PCR products generated using the FGPS-6/FGPL-132 primer pair. The results of NCBI BLAST comparative analysis with these sequences showed over $98 \%$ sequence identity with the rRNA gene represented in the published $\mathrm{Cmm}$ NCPPB382 complete genome sequence (Gartemann et al. 2008). The sequences were also divided into 16S rDNA and ITS regions and subjected to individual BLAST searches to analyze the variation at each locus. The $16 \mathrm{~S}$ rDNA sequences of all tested strains exhibited over $99 \%$ similarity with various $\mathrm{Cmm}$ strains. When comparing the $16 \mathrm{~S}$ rDNA sequences, only 19 positions out of 1,359 nucleotides (1.4\%) showed variation, and five of these positions showed grouped differences between tomato and pepper isolates (data not shown). In contrast, the sequences of the ITS region displayed relatively low similarities in the range of $94 \%$ to $98 \%$ (data not shown). In the ITS sequences, 33 positions showed variation, out of a total of 774 nucleotides (4.3\%). Of the 33 nucleotide positions showing variation, 17 positions $(51.5 \%)$ showed grouped differences between tomato and pepper isolates (Fig. 6).

To further characterize the genetic relationships of the pepper and tomato isolates in the context of the 

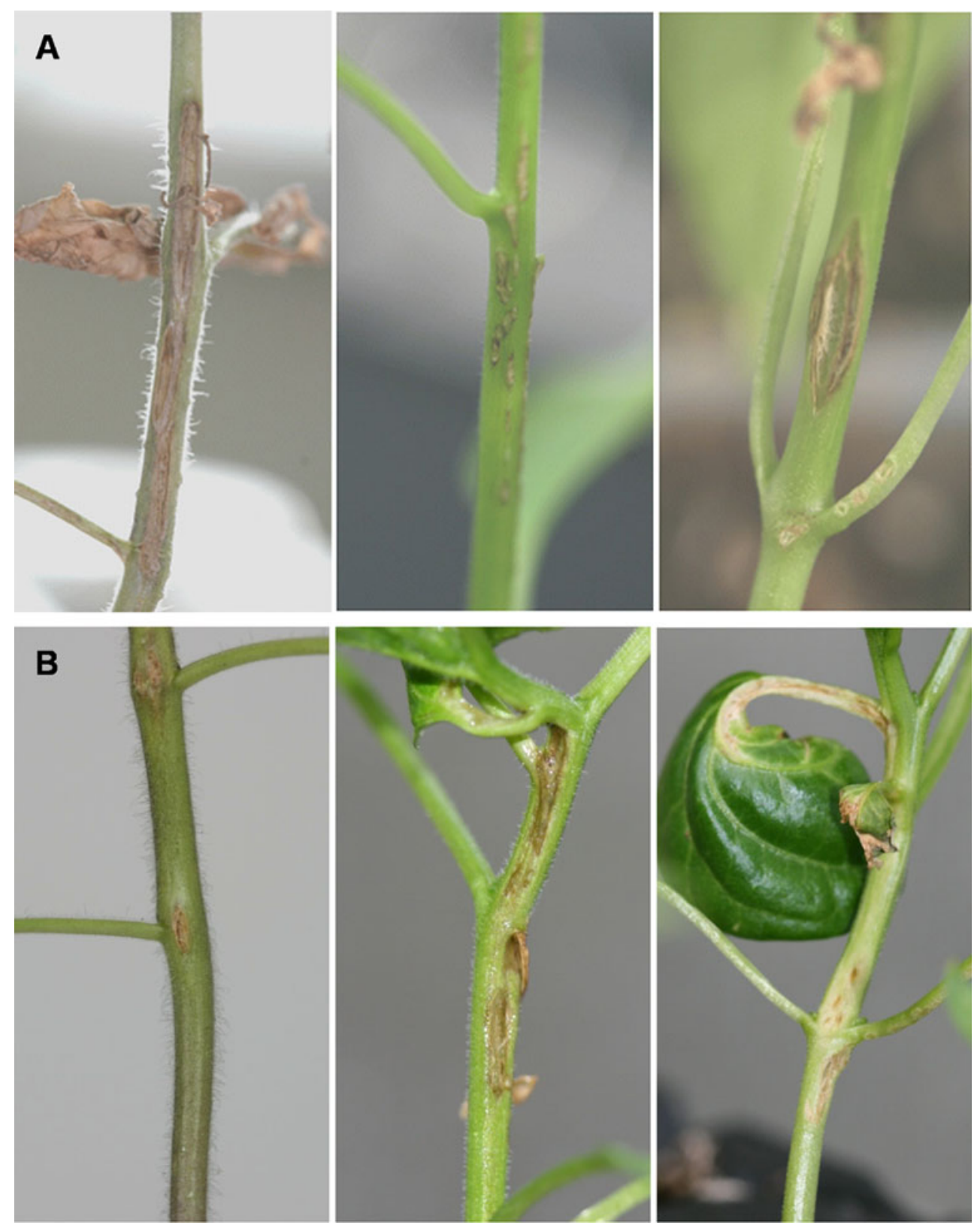

Fig. 3 Symptoms induced by Clavibacter michiganensis subsp. michiganensis isolates. a: tomato isolates (LMG7333); b: pepper isolates (PF007); Left: tomato; Middle: pepper; Right: bell pepper

five $C m$ subspecies, a phylogenetic analysis were performed on the basis of the 16S rDNA and ITS sequences. The phylogenetic trees demonstrated that pepper isolates formed a distinct group separate from tomato isolates. Further, unexpectedly, the similarity of the 16S rDNA and ITS sequences between the two $\mathrm{Cmm}$ groups was not much higher than that seen between Cm. subspecies (Fig. 7).
Detection of virulence related genes

The presence of the plasmid-borne virulence genes, celA and pat-1, was determined by PCR with various primers. We found that the two virulence genes could not be detected in any pepper isolates, whereas bands of the expected size from the pat-1 gene were generated in four of the six tomato isolates with $\mathrm{Cmm} 5 / \mathrm{Cmm} 6$ and 
Table 3 Symptoms of infection with Clavibacter michiganensis subsp. michiganensis isolates in 3 host plants at 25 days after inoculation

\begin{tabular}{|c|c|c|c|c|c|c|}
\hline \multirow[t]{2}{*}{ Symptoms } & \multicolumn{3}{|l|}{ Tomato isolates } & \multicolumn{3}{|c|}{ Pepper isolates } \\
\hline & Tomato & Pepper & Bell Pepper & Tomato & Pepper & Bell Pepper \\
\hline Wilting & $+++^{\mathrm{a}}(100 \%)^{\mathrm{b}}$ & - & - & - & - & - \\
\hline Stem canker & $+++(100 \%)$ & $+(20 \%)$ & $++(80 \%)$ & $++(50 \%)$ & $++(50 \%)$ & $++(70 \%)$ \\
\hline Leaf blight & $\mathrm{NA}^{\mathrm{c}}$ & $+(20 \%)$ & $+(30 \%)$ & $+(30 \%)$ & $+(30 \%)$ & $++(50 \%)$ \\
\hline Death & $+++(80 \%)$ & - & - & - & - & - \\
\hline
\end{tabular}

${ }^{\mathrm{a}}+,++,+++$ : refer to weakly, moderately and highly virulent reactions;-: absent of symptom

${ }^{\mathrm{b}}(\%)$ : percentage of plants showing symptom

${ }^{\mathrm{c}} N A$ not available

P1rep/P3rep primers, and all tomato isolates were also positive for the presence of celA gene with three primer pairs (Fig. 8). A nonspecific PCR product of about $1 \mathrm{~kb}$ was amplified in all pepper isolates when using the PFC3/PFC5 primer pair for amplification of the cellulose-binding domain of celA (Fig. 8-e). The sequence of this nonspecific product from pepper isolates PS003 (Accession no: JN603301), PS010 (Accession no: JN603302), and PS018 (Accession no: JN603303) showed a high similarity (94\%) with the uvrB gene of Cmm NCPPB382 (data not shown). PCR detection of four pathogenicity-related genes located on the PAI revealed that all tomato isolates were positive for these genes, whereas all pepper isolates lacked $\operatorname{ch} p \mathrm{C}$, chp $\mathrm{G}$, ppaA, and tom $\mathrm{A}$ (Fig. 9). These results might suggest that the pathogenic differences between the two
$\mathrm{Cmm}$ groups are associated with variations in these virulence-related genes.

Cellulase activity

The endoglucanase CelA of $\mathrm{Cmm}$ is known to be an important virulence factor required for wilt-induction capability on tomato. In this study, celA was not detected in any pepper isolates, and, consistent with this result, these isolates caused no wilting symptoms in the three hosts. To determine whether cellulase activity is absent in pepper isolates, a bioassay was carried out on M9CMC agar plates. Surprisingly, these isolates appeared to have much higher activity than tomato isolates on this medium (Fig. 10). These results suggest that another type of cellulase, which does not

Table 4 Shoot dry weight and colonization of 3 host plants infected by several tomato and pepper isolates of Clavibacter michiganensis subsp. michiganensis at 25 days after inoculation

\begin{tabular}{|c|c|c|c|c|c|c|}
\hline \multirow[t]{2}{*}{ Strain } & \multicolumn{3}{|c|}{ Dry weight (g/plant) } & \multicolumn{3}{|c|}{ Colonizatin (CFU/g FW) } \\
\hline & Tomato & Pepper & Bell-Pepper & Tomato & Pepper & Bell-Pepper \\
\hline LMG7333 & 0.56 & 0.63 & 0.43 & $1.6 \times 10^{9}$ & $5.5 \times 10^{5}$ & $2.1 \times 10^{7}$ \\
\hline LMG3681 & 0.82 & 0.55 & 0.42 & $7.5 \times 10^{8}$ & $2.6 \times 10^{6}$ & $3.9 \times 10^{8}$ \\
\hline LMG3687 & 0.68 & 0.68 & 0.46 & $3.0 \times 10^{8}$ & $2.6 \times 10^{6}$ & $3.9 \times 10^{8}$ \\
\hline LMG3679 & 0.66 & 0.64 & 0.40 & $3.0 \times 10^{8}$ & $1.6 \times 10^{6}$ & $2.0 \times 10^{8}$ \\
\hline TS004 & 0.69 & 0.62 & 0.40 & $2.8 \times 10^{8}$ & $4.7 \times 10^{6}$ & $2.9 \times 10^{8}$ \\
\hline PS003 & 1.12 & 0.48 & 0.38 & $1.7 \times 10^{5}$ & $2.1 \times 10^{8}$ & $3.9 \times 10^{8}$ \\
\hline PF007 & 1.04 & 0.54 & 0.43 & $1.1 \times 10^{6}$ & $2.3 \times 10^{8}$ & $1.8 \times 10^{8}$ \\
\hline PF008 & 1.03 & 0.51 & 0.41 & $1.0 \times 10^{6}$ & $5.0 \times 10^{8}$ & $1.6 \times 10^{8}$ \\
\hline Negative control & 1.26 & 0.72 & 0.62 & 0 & 0 & 0 \\
\hline
\end{tabular}




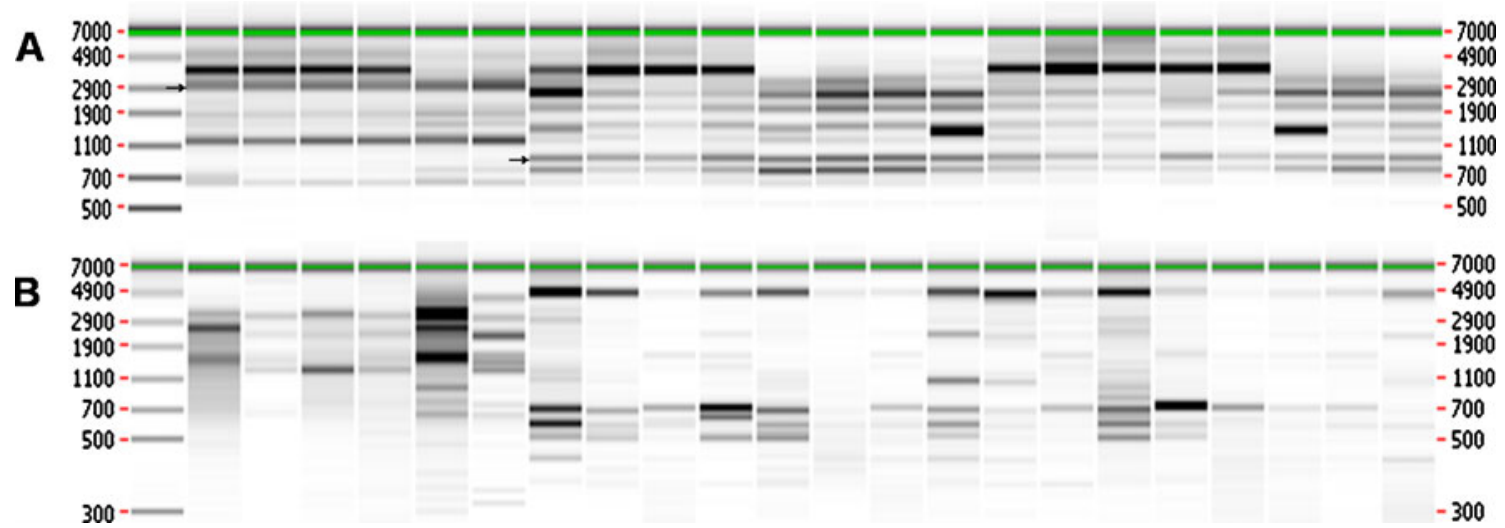

Fig. 4 Rep-PCR fingerprint patterns of Clavibacter michiganensis subsp. michiganensis strains isolated from tomato and pepper. a: BOX-PCR; b: ERIC-PCR; M: molecular marker

have any impact on wilt induction, is present in pepper isolates.

\section{Discussion}

Bacterial canker caused by $\mathrm{Cmm}$ has been reported in commercial pepper, bell pepper, and eggplant fields in Israel, Italy, Japan, Korea, Lithuania, and the USA. However, this disease has received little attention, perhaps because infected plants do not generally die, and therefore damage and economic losses are relatively limited (Burokiene et al. 2005; Buonaurio et al.
1999; Kobayashi and Kijima 1981; Lai 1976; Latin et al. 1995; Lewis-Ivey and Miller 2000; Lee et al. 1999; Medina-mora et al. 2000; Volcani et al. 1970). Although some cases of $\mathrm{Cmm}$ in pepper plants had been reported previously, analysis of characteristics such as pathogenicity and genetic diversity had not been performed sufficiently, in many cases because the inoculum source was assumed to come from nearby tomato fields.

In this study, the comparison of pepper and tomato isolates revealed a high diversity of pathogenic properties as well as colony morphology. $\mathrm{Cmm}$ isolates from pepper consistently produced orange-coloured

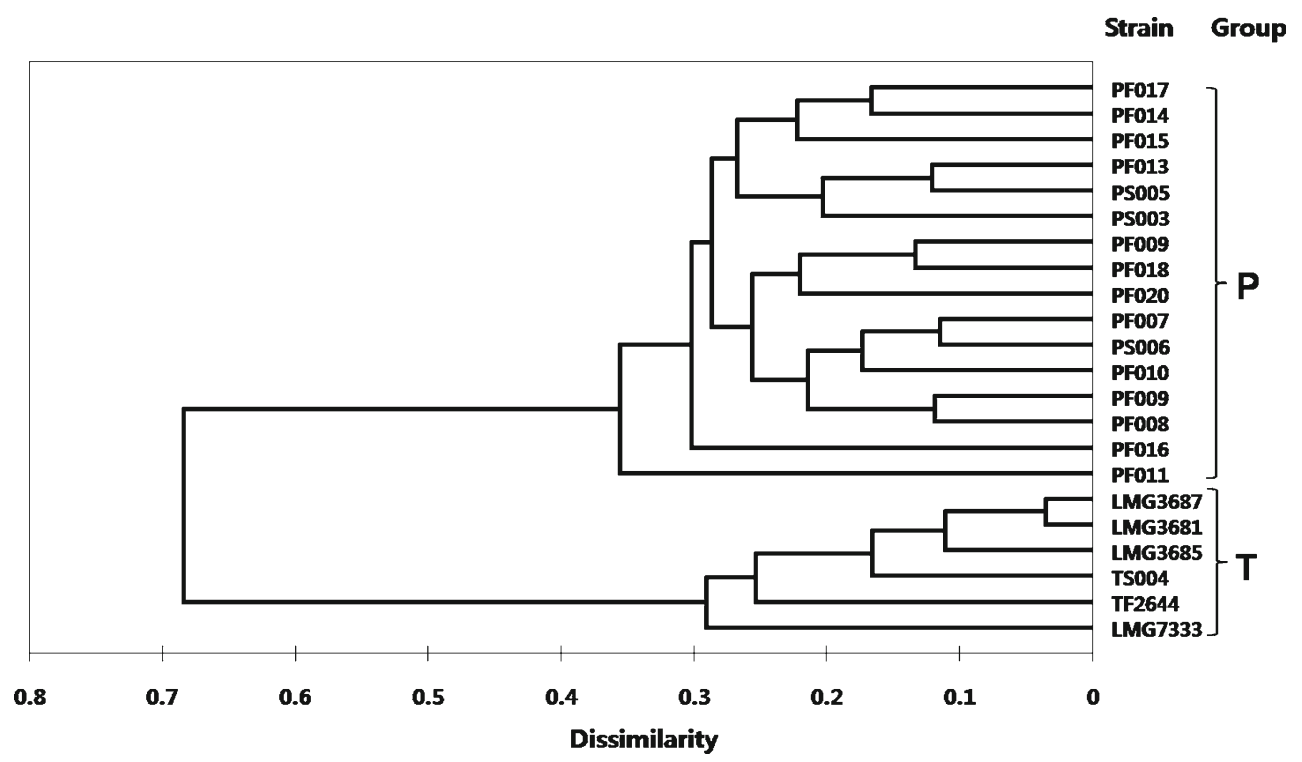

Fig. 5 Dissimilarity UPGMA tree derived from rep-PCR fingerprint patterns of Clavibacter michiganensis subsp. michiganensis. T: tomato isolates group; P: pepper isolates group 
1

LMG7333

TS2644

LMG3681

TS004

LMG3679

LMG3687

LMG3685

PSO03

PSO06

PSO05

PF007

PF008

LMG7333

TS2644

LMG3681

TS004

LMG3679

LMG3687

LMG3685

PSO03

PSO06

PSO05

PF007

PF008

LMG7333

TS2644

LMG3681

TS004

LMG3679

LMG3687

LMG3685

PSO03

PSO06

PSO05

PFO07

PF008

LMG7333

TS2644

LMG3681

TS004

LMG3679

LMG3687

LMG3685

PSO03

PSO06

PSO05

PF007

PF008

LMG7333

TS2644

LMG3681

TSO04

LMG3679

LMG3687

LMG3685

PSO03

PSO06

PSO05

PF007

PF008

LMG7333

TS2644

LMG3681

TSOO4

LMG3679

LMG3687

LMG3685

$\mathrm{PSO03}$

PSO06

PSO05

PF007

PF008

Fig. 6 Comparison of the nucleotide sequences of the ITS region between tomato and pepper isolates of Clavibacter michiganensis subsp. michiganensis. The nucleotide areas showing grouped differences are boxed

GGTTCCCTCTACCCGCCCTATATATTCAGGCGGGAGTCACCAGGTCACCCAAAGGGCCTGGCGGGGTTTCCCCATTCGGAGATCCTCGGATCAAAGCTCTATTATCAGCTCCCCGAGGCTTATCGCAGAT

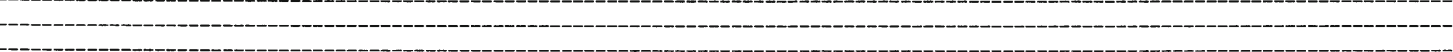

-

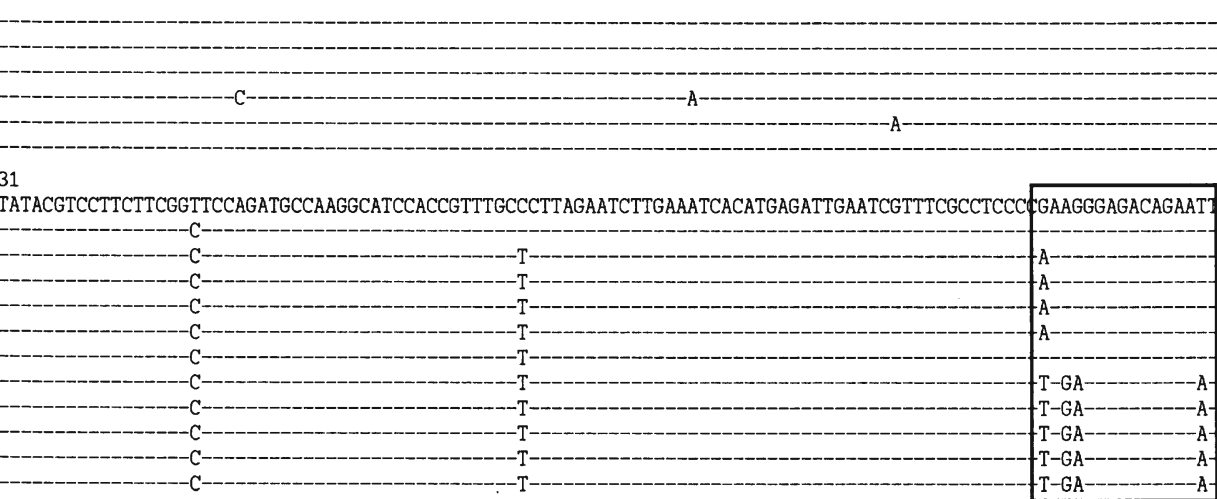

ICTTTGTGATCCACCGGAAAACCGGTGAATCTAAGATGCTCGCGTCCACTGTGTAGTTCTCAATATACGGGCGGTACCCCACCATCATCCACAACAGGACGACGGAAAGGGTCCGACAAGAAACCAGACA

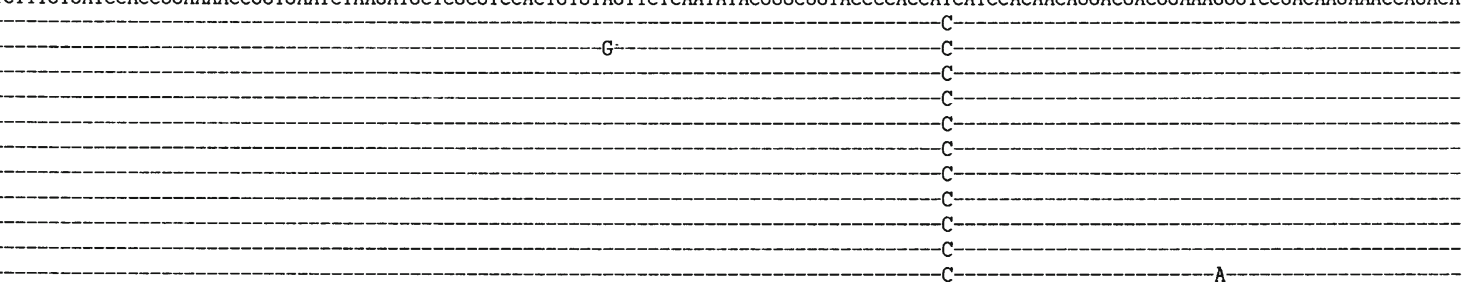

391

CACCCAG A GTGGGGCCCGGTCCCTCAGGACCCAACAGCGTGCAACATGCCCTCGACACA CCAG-ACCACGTTCCCAdCCCACAAGGAGGCGTACTAGCAG CCGA ACATCAGCCGGCATCAATGTC

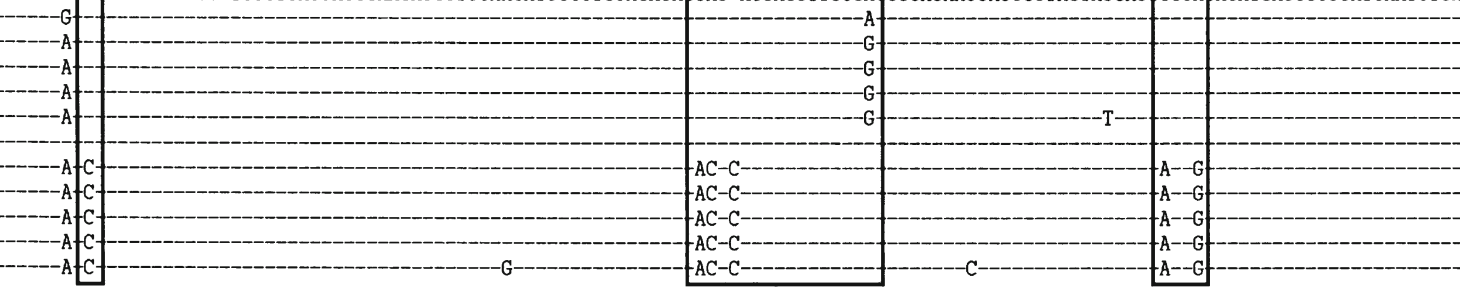

ATGTTCCACCCATGAGCGCCAC GCCAGAACAG CGCCTGACGCGTGACTTGGCACCCTTGATCTCCCT TA TACAGAGgAGAGGTGCACATGCTCCTTAGAAAGGAGGTGATCCAGCCGCACCTTCCGG

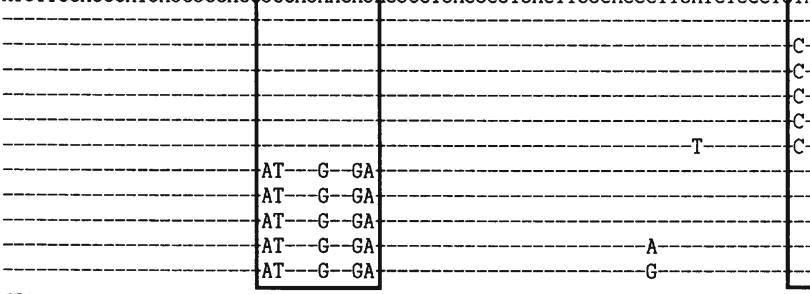

651

AT---G--GA

-

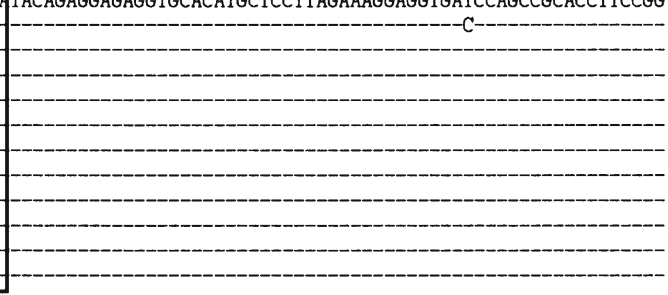

ACGGCTACCTTGTTACGACTTAGTCCTAATCACCGATCCCACCTTCGACAGCTCCTCCCTTGCGGTACGCCACTGGCTTCGGGTGTTACGACTTTCATGACTTGACGGCGGTGTGTACAA

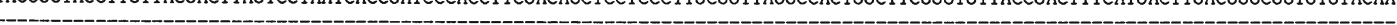
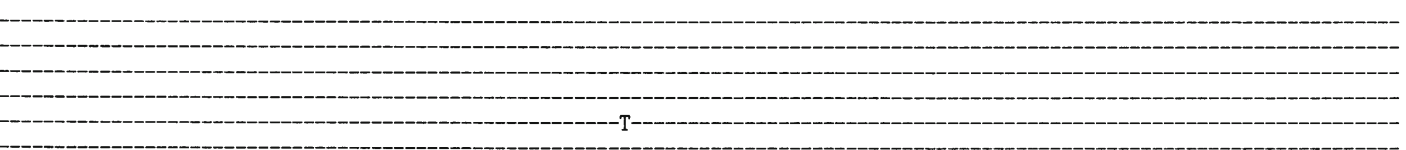

$-$ 

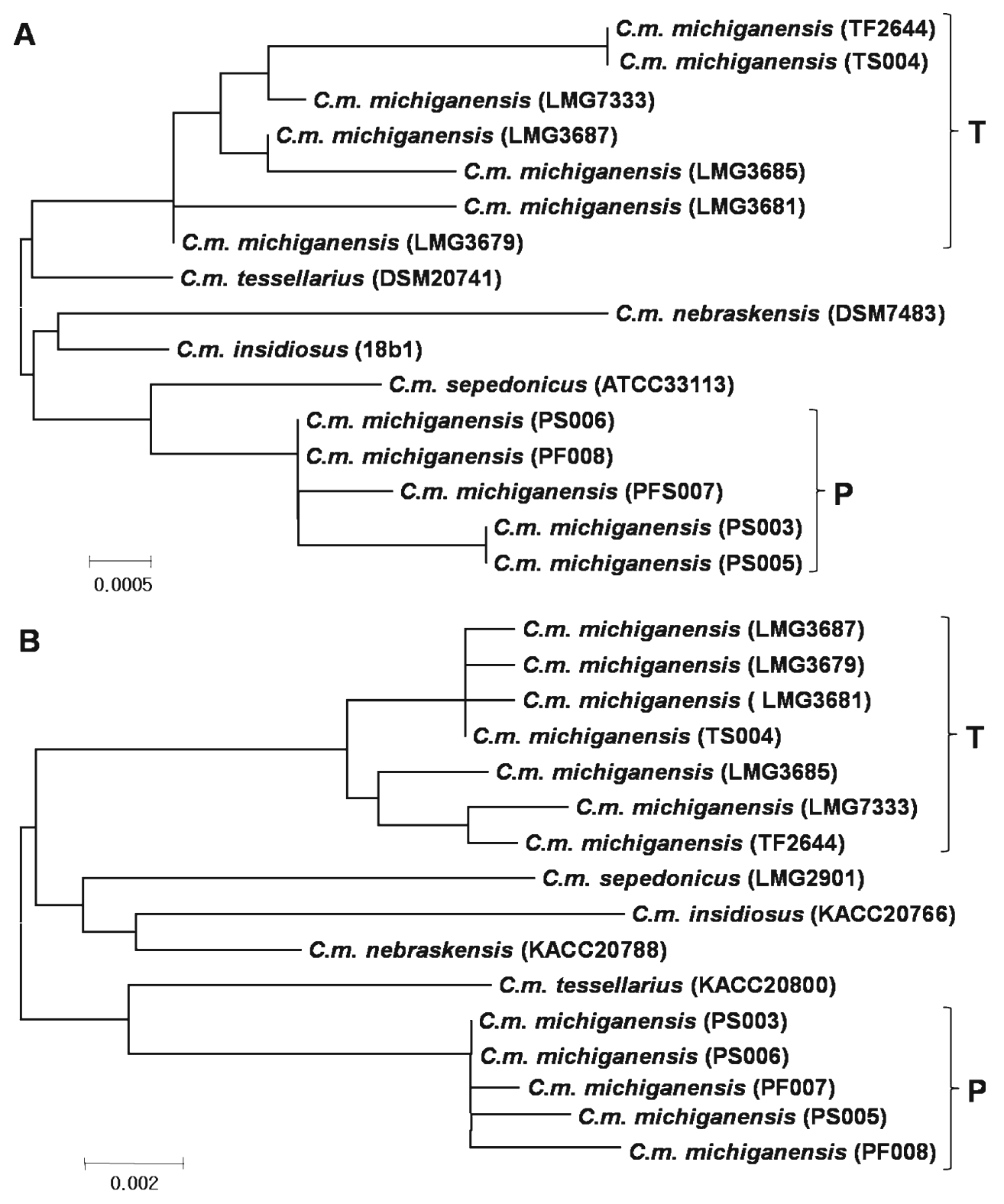

Fig. 7 Neighbour-joining tree derived from 16S rDNA (a) and ITS region (b) sequence analysis of Clavibacter michiganensis subspecies. T: tomato isolates; P: pepper isolates. The following $16 \mathrm{~S}$ rDNA sequences in GenBank were used: C.m. subsp.

colonies rather than yellow. However, although these morphological variations have been reported previously (Kaneshiro et al. 2006), the correlation between pathogenicity and morphology of $\mathrm{Cmm}$ was not revealed. Upon inoculation on pepper, atypical strains isolated from pepper showed higher virulence and colonization efficiency ( $>100$ times) than tomato isolates, whereas sepedonicus ATCC33113 (Accession no. AM849034); C.m. subsp. insidiosus 18b1 (Accession no. GQ332310); C.m. subsp. nebraskensis DSM7483 (Accession no. AM410697); C.m. subsp. tessellarius DSM20741 (Accession no. AM410693)

they showed significantly reduced pathogenicity on tomato seedlings than tomato isolates. These correlations between virulence and host origin could be demonstrated by host preference, which was recognized through Korean quarantine inspection statistics. $\mathrm{Cmm}$ strains showing orange colonies have been isolated from pepper seeds but only in one case from tomato seeds, 


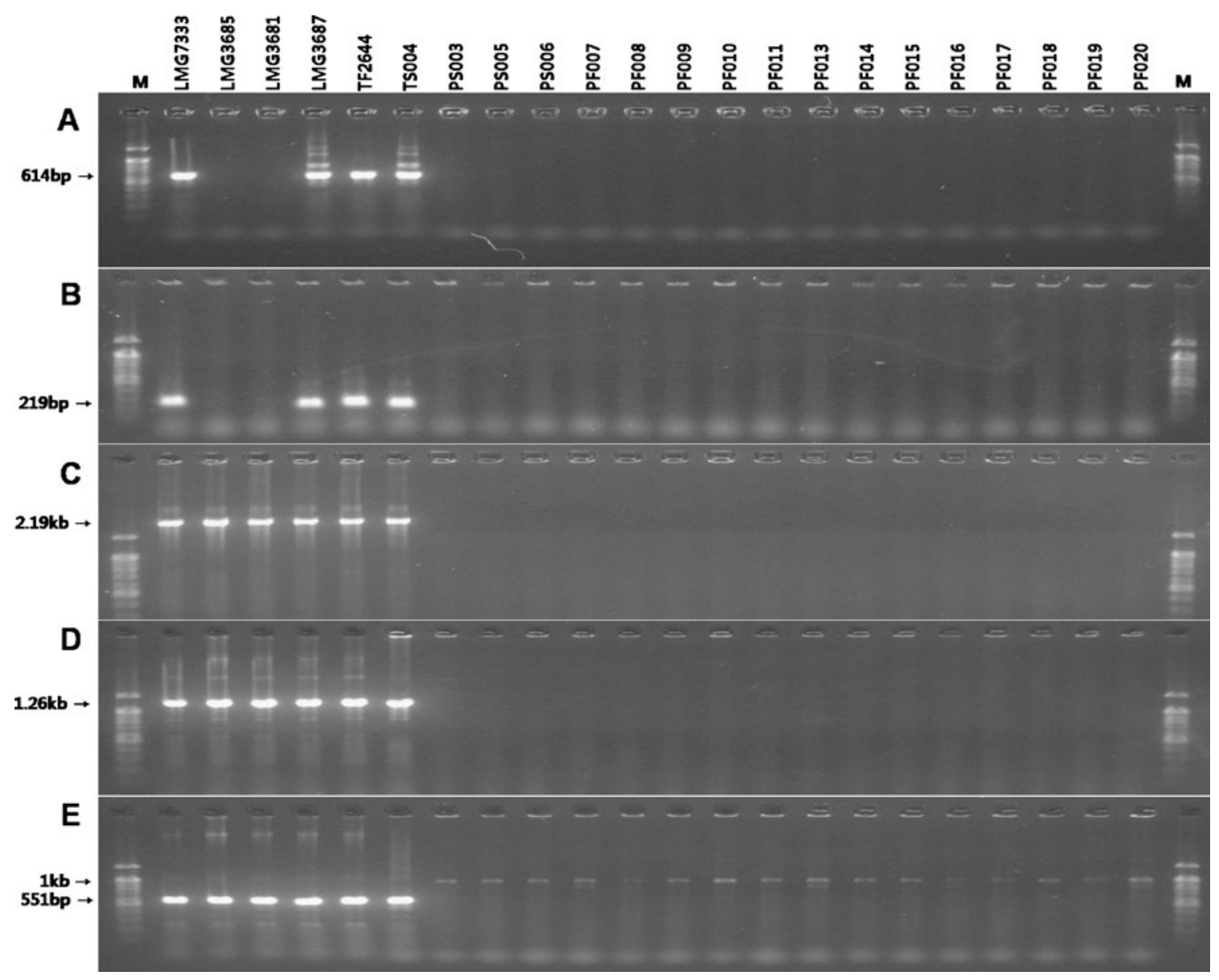

Fig. 8 PCR assay for detection of pat-1 and celA genes from Clavibacter michiganensis subsp. michiganensis strains isolated from tomato and pepper. a pat-1 gene with $\mathrm{Cmm} 5 / \mathrm{Cmm} 6$ primers; b pat-1 gene with P1rep/P3rep primers; c celA gene with

while the typical pale yellow $\mathrm{Cmm}$ strains were isolated only from tomato seeds but never detected on pepper seeds.

The pepper isolates, which show relatively low mucoidy, did not induce wilting symptoms in either tomato or pepper, and consequently caused less reduction in shoot dry weight. The mucoid and non-mucoid strains of Cms are known to differ in terms of the amount and composition of their extracellular polysaccharides (EPS). The composition of EPS can affect antigenic properties, colonization of host, and induction of wilting symptoms, as well as colony morphology of Cms (Fousek and Mraz 2003; Gartemann et al. 2003). However, EPS content may not be a significant factor affecting the antigenic properties of $\mathrm{Cmm}$ strains, because all $\mathrm{Cmm}$ isolates in this study 578up/2752low primers; d celA gene with pCRcel593/ pCRcel1860 primers; E: celA gene with PFC3/PFC5 primers; $\mathrm{M}$ : molecular marker

responded to commercial antibody at a similar range of $\mathrm{OD}_{\mathrm{A} 405}$ values, and no significant differences were found between the fatty acid profiles of the $2 \mathrm{Cmm}$ groups in this study. Although two plasmid-borne genes and the chromosomal PAI were known to be involved in the pathogenicity of $\mathrm{Cmm}$, it was also reported that some avirulent strains respond positively, while virulent strains respond negatively to PCR primers for these virulence-related genes (Bella et al. 2007; Kleitman et al. 2008). In this study, none of the pepper isolates gave PCR products with celA or pat-1 primers. Moreover, four virulence-related genes residing on the PAI could not be detected in any pepper isolates by PCR. These results may explain the differences of pathogenicity between the two $\mathrm{Cmm}$ groups. However, all pepper isolates still 


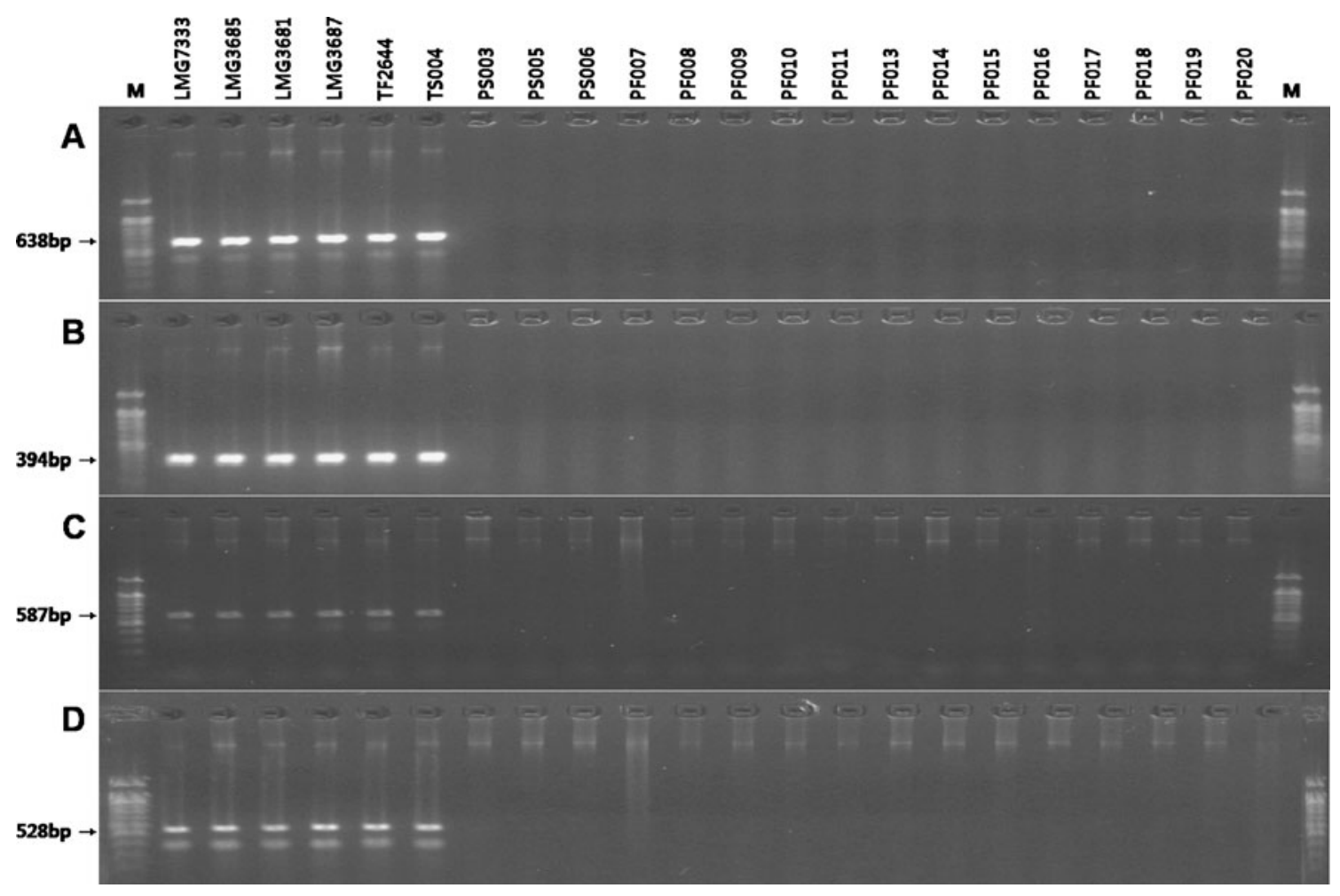

Fig. 9 PCR assay for detection of virulence-related genes residing on the pathogenicity island of Clavibacter michiganensis subsp. michiganensis strains. a chpC gene with
chpC-F/chpC-R primers; b chpG gene with chpG-F/chpG-R primers; c ppaA gene with ppaA-F/ppaA-R primers; d tom $\mathrm{A}$ gene with tomA-F/tomA-R primers; M: molecular marker showed high cellulase activity in bioassay. Therefore, further studies are required in order to determine whether the non-wilting of pepper isolates is associated with EPS composition, variation in virulencerelated genes, or type of cellulase.
The rep-PCR method has been used to detect genetic variability even between single bacterial strains; for example, between $\mathrm{Cmm}$ and Cms subspecies (Fousek and Mraz 2003; Louws et al. 1998). In a previous study on $\mathrm{Cms}$, no genetic differences

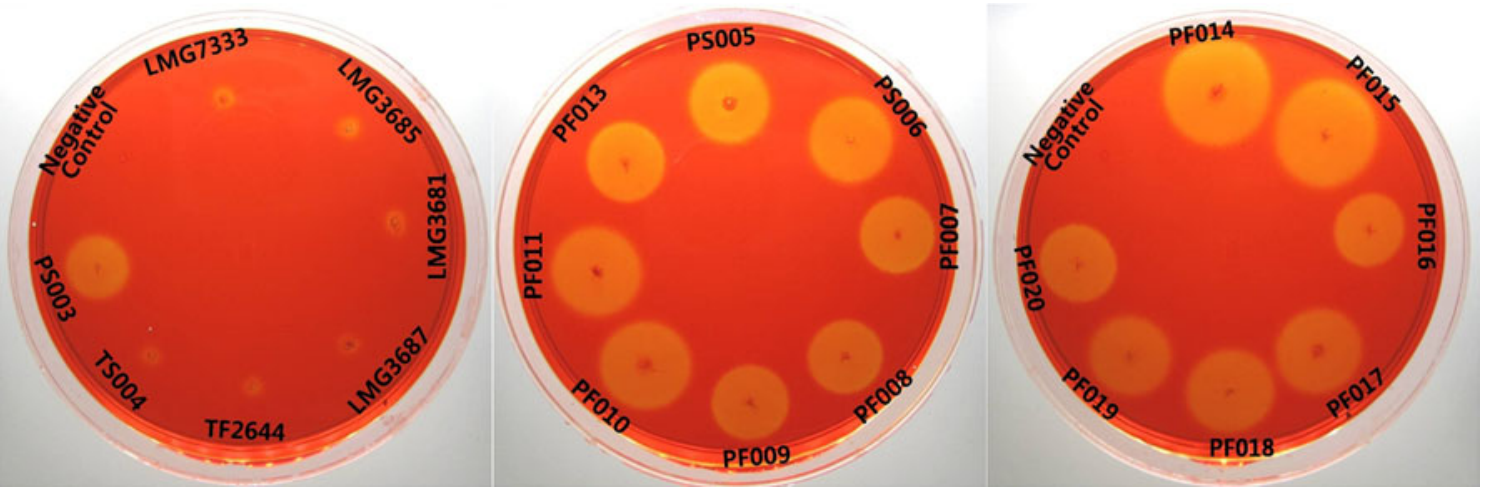

Fig. 10 Bioassay for cellulase activity of Clavibacter michiganensis subsp. michiganensis strains on M9CMC agar plates stained with $0.1 \%$ Congo red and washed with $1 \mathrm{M} \mathrm{NaCl}$ 
between mucoid and non-mucoid strains could be detected by rep-PCR (Fousek and Mraz 2003). However, in this study, genetic differences between tomato isolates and pepper isolates were identified by genomic fingerprinting.

Analysis of the $16 \mathrm{~S}$ rDNA sequence has been widely used as a taxonomic tool for bacteria, including unculturable species. In this study, the average similarity value of $16 \mathrm{~S}$ rDNA sequences among $\mathrm{Cmm}$ strains was $99.5 \%$, indicating that all tested isolates may be similar enough to be identified as part of a single subspecies. However, it was reported that the $16 \mathrm{~S}$ rDNA sequence analysis cannot accurately identify strains of Cmm (Kaneshiro et al. 2006) due to highly similar 16S rDNA sequences between different $\mathrm{Cm}$ subspecies (Lee et al. 1997b; Suzuki et al. 1996). Considering such high similarity between the five subspecies, the presence of grouped differences in 16S rDNA between pepper and tomato isolates could give new meaning to classification of pepper isolates at the subspecies level.

The evolution of the ITS region is much faster than that of the $16 \mathrm{~S}$ rDNA genes, probably due to reduced functional restriction. Thus, ITS sequence analysis has been used as a means to trace more recent evolutionary events at species and strain level. Pastrik et al. compared the sequences of six $\mathrm{Cmm}$ isolates from Europe and showed that $\mathrm{Cmm}$ has little variation in the ITS region (Pastrik and Rainey 1999). However, in the present study, tomato and pepper isolates could be separated into two distinct groups by ITS analysis according to their host origin. Over 50\% of the variation in ITS sequences showed grouped differences between tomato and pepper isolates. These distinct dissimilarities in the ITS region between the two groups may explain why all pepper isolates were weakly amplified with the $\mathrm{Cmm}$-specific primer, ClaF1/ClaR2, which is based on ITS sequences. In addition, these results suggest that these groups have followed individual paths of evolution within each host. Furthermore, the classification of the pepper isolates as a new subspecies could be proposed on the basis of genetic dissimilarity, since the 16S rDNA and ITS sequences between the two $\mathrm{Cmm}$ groups showed relatively low similarity in the context of that seen between the five different $\mathrm{Cm}$ subspecies.

Genetic variations between populations of $\mathrm{Cmm}$ have consistently been reported from various countries, and these results have been used to estimate their origins (De Leon et al. 2009; Ignatov et al. 2004; Kaneshiro et al. 2006; Nazari et al. 2007). Pepper isolates could have long existed in pepper fields undiscovered because they were not usually a major disease problem. In addition, bacterial canker may be hard to detect in the case of co-infection with other diseases such as bacterial leaf spot (Xanthomonas campestris pv. vesicatoria), which is one of the most common and destructive diseases of peppers. These disease symptoms are indistinguishable in mixed infection, and the different growth rates of two bacterial pathogens on an agar plate may easily cause $\mathrm{Cmm}$ to be overlooked. Therefore, it is very likely that the atypical pepper isolates may represent a separate $\mathrm{Cmm}$ population that has existed preferentially on pepper plants in Asian countries, since peppers are more commonly cultivated in Asia than in Western countries.

Acknowledgements This work was funded by the National Plant Quarantine Service of Korea.

Open Access This article is distributed under the terms of the Creative Commons Attribution Noncommercial License which permits any noncommercial use, distribution, and reproduction in any medium, provided the original author(s) and source are credited.

\section{References}

Bella, P., Ialacci, G., Licciardello, G., \& Catara, V. (2007). Detection of atypical strains of Clavibacter michiganensis subsp. michiganensis in greenhouse tomatoes in Sicily. Journal of Plant Pathology, 89(3), S30.

Buonaurio, R., Stravato, V. M., \& Scorthchini, M. (1999). Le malattie batteriche del peperone. Informatore Fitopatologico, 49(5), 13-19.

Burger, A., Grafen, I., Engemann, J., Niermann, E., Pieper, M., Kirchner, O., Gartemann, K., \& Eichenlaub, R. (2005). Identification of homologues to the pathogenicity factor pat-1, a putative serine protease of Clavibacter michiganensis subsp. michiganensis. Microbiological Research, 160, 417-427.

Burokiene, D., Sobiczewski, P., \& Berczynski, S. (2005). Phenotypic characterization of Clavibacter michiganensis subsp. michiganensis isolates from Lithuania. Phytopathologia Polonica, 38, 63-77.

Davis, M. J., \& Vidaver, A. K. (2001). Coryneform plant pathogens. In N. W. Schaad (Ed.), Laboratory guide for identification of plant pathogenic bacteria (3rd ed., pp. 218-235). St. Paul: The American Phytopathological Society.

De Leon, L., Rodriguez, A., Llop, P., Lopez, M. M., \& Siverio, F. (2009). Comparative study of genetic diversity of Clavibacter michiganensis subsp. michiganensis isolates from the Canary Islands by RAPD-PCR, BOX-PCR and AFLP. Plant Pathology, 58(5), 862-871.

Dreier, J., Bermpohl, A., \& Eichenlaub, R. (1995). Southern hybridization and PCR for specific detection of 
phytopathogenic Clavibacter michiganensis subsp. michiganensis. Phytopathology, 85(4), 462-468.

Dreier, J., Meletzus, D., \& Eichenlaub, R. (1997). Characterization of the plasmid encoded virulence region pat-1 of phytopathogenic Clavibacter michiganensis subsp. michiganensis. Molecular Plant-Microbe Interactions, 10(2), 195-206.

Fousek, J., \& Mraz, I. (2003). Determination of genetic differences between fluid and nonfluid variants of Clavibacter michiganensis subsp. sepedonicus using rep-PCR technique. Folia Microbiologica, 48(5), 682-686.

Gartemann, K. H., Kirchner, O., Engemann, J., Grafen, I., Eichenlaub, R., \& Burger, A. (2003). Clavibacter michiganensis subsp. michiganensis: first steps in the understanding of virulence of a Gram-positive phytopathogenic bacterium. Journal of Biotechnology, 106, 179-191.

Gartemann, K. H., Abt, B., Beke, T., Burger, A., Engemann, J., Flugel, M., Gaigalat, L., Goesmann, A., Grafen, I., Kalinowski, J., Kaup, O., Kirchner, O., Krause, L., Linke, B., McHardy, A., Meyer, F., Pohle, S., Ruckert, C., Schneiker, S., Zellermann, E., Puhler, A., Eichenlaub, R., Kaiser, O., \& Bartels, D. (2008). The genome sequence of the tomato-pathogenic actinomycete Clavibacter michiganensis subsp michiganensis NCPPB382 reveals a large island involved in pathogenicity. Journal of Bacteriology, 190(6), 2138-2149.

Gleason, M. L., Gitaitis, R. D., \& Ricker, M. D. (1993). Recent progress in understanding and controlling bacterial canker of tomato in Eastern North America. Plant Disease, 77(11), 1069-1076.

Hayward, A. C., \& Waterston, J. M. (1964). Corynebacterium michiganense. Descriptions of pathogenic fungi and bacteria no. 19. Wallingford: CAB International.

Ignatov, A., Matveeva, E., \& Schaad, N. (2004). Genetic diversity among Clavibacter michiganensis subsp. Michiganensis and subsp. sepedonicus in Russian Federation. Phytopathology, 94, 543.

Jahr, H., Dreier, J., Meletzus, D., Bahro, R., \& Eichenlaub, R. (2000). The endo- $\beta$-1,4-glucanase CelA of Clavibacter michiganensis subsp. michiganensis is a pathogenicity determinant required for induction of bacterial wilt of tomato. Molecular Plant-Microbe Interactions, 13(7), 703-714.

Kaneshiro, W. S., \& Alvarez, A. M. (2001). Specificity of PCR and ELISA assays for hypovirulent and avirulent Clavibacter michiganensis subsp. michiganensis. Phytopathology, 91, S46.

Kaneshiro, W. S., Mizumoto, C. Y., \& Alvarez, A. M. (2006). Differentiation of Clavibacter michiganensis subsp. michiganensis from seed-borne saprophytes using ELISA, Biolog and 16S rDNA sequencing. European Journal of Plant Pathology, 116(1), 45-56.

Kleitman, F., Barash, I., Burger, A., Iraki, N., Falah, Y., Sessa, G., Weinthal, D., Chalupowica, L., Gartemann, K. H., Eichenlaub, R., \& Manulis-Sasson, S. (2008). Characterization of a Clavibacter michiganensis subsp. michiganensis population in Israel. European Journal of Plant Pathology, $121,463-475$.

Kobayashi, M., \& Kijima, T. (1981). Occurrence of bacterial canker (temporary name) of sweet pepper in Japan. Proceedings of the Kanto-Tosan Plant Protection Society, $28,54$.
Kostman, J. R., Edlind, T. D., Lipuma, J. J., \& Stull, T. L. (1992). Molecular epidemiology of Pseudomonas cepacia determined by polymerase chain reaction ribotyping. Journal of Clinical Microbiology, 30, 2084-2087.

Kumar, S., Tamura, K., \& Nei, M. (2004). MEGA 3: integrated software for molecular evolutionary genetics analysis and sequence alignment. Briefings in Bioinformatics, 5, 150-163.

Lai, M. (1976). Bacterial canker of bell pepper caused by Curtobacterium michiganensis. Plant Disease Reporter, 60, 339-342.

Latin, R., Tikhonova, I., \& Rane, K. (1995). First report of bacterial canker of pepper in Indiana. Plant Disease, 79(8), 860.

Lee, I. M., Bartoszyk, I. M., Gundersen, D. E., Mogen, B., \& Davis, R. E. (1997a). Nested PCR for ultrasensitive detection of the potato ring rot bacterium, Clavibacter michiganensis subsp. sepedonicus. Applied and Environmental Microbiology, 63(7), 2625-2630.

Lee, I. M., Bartoszyk, I. M., Gundersen-Rindal, D. E., \& Davis, R. E. (1997b). Phylogeny and classification of bacteria in the genera Clavibacter and Rathayibacter on the basis of $16 \mathrm{~S}$ rRNA gene sequence analysis. Applied and Environmental Microbiology, 63, 2631-2636.

Lee, S. D., Yoon, C. M., Lee, Y. K., Choi, Y. C., \& Cho, Y. S. (1999). Occurrence and distribution of bacterial canker of red pepper caused by Clavibacter michiganensis subsp. michignensis. Plant Disease and Agriculture, 5(2), 105-110.

Lewis-Ivey, M. L., \& Miller, S. A. (2000). First report of bacterial canker of pepper in Ohio. Plant Disease, 84(7), 810-811.

Louws, F. J., Bell, J., Medina-Mora, C. M., Smart, C. D., Opgenorth, D., Ishimaru, C. A., Hausbeck, M. K., de Bruijn, F. J., \& Fulbright, D. W. (1998). rep-PCR-mediated genomic fingerprinting: a rapid and effective method to identify Clavibacter michiganensis. Phytopathology, 88, 862-868.

Medina-Mora, M., Hausbeck, M. K., \& Fulbright, D. W. (2000). Rep-PCR analysis of Clavibacter michiganensis subsp. michignensis from peppers. Phytopathology, 90, S51.

Meletzus, D., Bermpohl, A., Dreier, J., \& Eichenlaub, R. (1993). Evidence for plasmid-encoded virulence factors in the phytopathogenic bacterium Clavibacter michiganensis subsp. michignensis NCPPB382. Journal of Bacteriology, 175(7), 2131-2136.

Nazari, F., Niknam, G. R., Ghasemi, A., Taghavi, S. M., Momeni, H., \& Torabi, S. (2007). An investigation on strains of Clavibacter michiganensis subsp. michignensis in north and North West of Iran. Journal of Phytopathology, 155, 563-569.

Normand, P., Cournoyer, B., Simonet, P., \& Nazaret, S. (1992). Analysis of a ribosomal operon in the actinomycete Frankia. Gene, 111, 119-124.

Pastrik, K. H., \& Rainey, F. A. (1999). Identification and differentiation of Clavibacter michiganensis subsp. michignensis by polymerase chain reaction-based techniques. Journal of Phytopathology, 147, 687-693.

Peng, F., Guo, Y. H., Shang, X. M., \& Guo, J. H. (2005). Development of a PCR assay for the detection of $\mathrm{Cmm}$. Jiangsu Journal of Agricultural Society, 21(2), 118-122.

Poysa, V. (1993). Evaluation of tomato breeding lines resistant to bacterial canker. Canadian Journal of Plant Pathology, $15,301-304$. 
Santos, M. S., Cruz, L., Norskov, P., \& Rasmussen, O. F. (1997). A rapid and sensitive detection of in tomato seeds by polymerase chain reaction. Seed Science and Technology, 25, 581-584.

Saitou, N., \& Nei, M. (1987). The neighbor-joining method: a new method for reconstructing phylogenetic trees. Molecular Biology and Evolution, 4, 406-425.

Stork, I., Gartemann, K. H., Burger, A., \& Eichenlaub, R. (2008). A family of serine proteases of Clavibacter michiganensis subsp. michignensis: chpC plays a role in colonization of the host plant tomato. Molecular Plant Pathology, 9(5), 599-608.

Suzuki, K., Sasaki, J., Uramoto, M., Nakase, T., \& Komagata, K. (1996). Agromyces mediolanus sp. nov., nom. rev., comb. nov., a species for "Corynebacterium mediolanum" Mamoli 1939 and for some aniline-assimilating bacteria with contain 2,4-diaminobutyric acid in the cell wall peptidoglycan. International Journal of Systemic Bacteriology, 46(1), 88-93.

Thompson, J. D., Higgins, D. G., \& Gibson, T. J. (1994). Clustal $\mathrm{W}$ : improving the sensitivity of progressive multiple sequence alignment through sequence weighting, position-specific gap penalties and weight matrix choice. Nucleic Acids Reserch, 22, 4673-4680.

Volcani, Z., Zutra, D., \& Cohn, R. (1970). A new leaf and fruit spot disease of pepper caused by Corynebacterium michiganense. Plant Disese Reporter, 54, 804-806.

Waleron, M., Waleron, K., Kamasa, J., Przewodowski, W., \& Lojkowska, E. (2011). Polymorphism analysis of housekeeping genes for identification and differentiation of Clavibacter michiganensis subspecies. European Journal of Plant Pathology, 131(2), 341-354. 